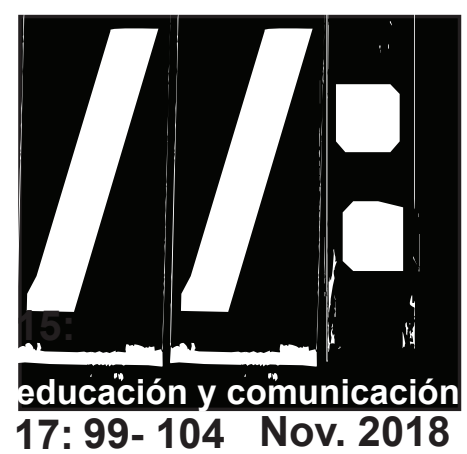

IN DELIRIUM... FORMAS DE ENTENDER LA EDUCACIÓN, LA COMUNICACIÓN Y LA VIDA In delirium ... Ways to understand education, communication and life

\author{
Jerônimo Jorge Cavalcante Silva. \\ Profesor en el Campus IV. \\ Universidad del Estado de Bahia (Brasil) \\ Posdoctorado en la Universidad de Cádiz (Epaña) \\ E.mail: jorgeazul53@gmail.com \\ Salas, Oliver \\ Universidad de Cádiz (España) \\ E.mail: creacionesmuscaria@gmail.com
}

Resumen:

Hablar en voz alta sobre el monstruo no es nada nuevo pero hacerlo desde la postura del que siente y padece puede resultar desacostumbrado. El delirio como alteración de la mente nos lleva a pensar en voz alta y a permitirnos decir cosas que, en estado de plenitud mental, nos hubiesen tachado de idiotas. He aquí una reflexión sobre las formas que existen en la educación, la comunicación y la vida. Es decir, tres patas que sujetan el techo artesonado y que, simplificando y sustituyendo el yo por el nosotros, deberían hacernos comprender la objetividad o subjetividad de la sensatez de lo que se dice. A todas luces, un viaje a través de las formas que se inspiran en la comprensión, en los sentimientos, en el soñar y en el creer.

Palabras claves: educación, comunicación, fantasía, ficción

\title{
Abstract:
}

Speaking aloud about the monster is nothing new. But doing it from the position of the one who feels and suffers can be unaccustomed. Delirium as an alteration of the mind leads us to reflect aloud. To allow us to say things that in a state of mental fullness would have labeled us an idiot. A thought about the forms that exist about education, communication and life. That is, three legs that hold the coffered ceiling in a way to give it to understand, simplifying and replacing the self with the we, objectivity or subjectivity for the wisdom of what it says. Clearly, a journey through forms that are inspired by understanding, feelings, dreaming and believing.

Keywords: education, communication, fantasy, fiction

Recibido 11-06-2018 / Revisado 25-06-2018 / Aceptado 19-07-2018 / Publicado 01-11-2018

https://doi.org/10.25267/Hachetetepe.2018.v2.i17.11 


\section{II: Educación y comunicación en los mundos de fantasía y ficción}

"teatro de la vida, o en el espejo del mundo".

Foucault

\section{Presentación}

$\mathrm{R}$ epensemos la educación desde el hecho plausible del desaprender. Cuestionemos la comunicación a partir de la interacción imprecisa de dos sujetos que intercambian lo más poderoso de su ser: la información. Y entre el hecho de desaprender y la generosidad de comunicar acontece al saber -un acto sin parangón que se ancla sobre dar sin contener la intención de recibir-. Este, en el horizonte cercano la vida, se erige como una altiplanicie que se prolonga entre el tiempo y es ahí, in tempore, cuando las cosas cambian, evolucionan o se derrotan.

In delirium, es un artículo de opinión inspirada en la soberbia; en la innecesaria aceptación de lo que no nos fue consultado y en el rechazo a lo que se cuestiona y soslaya; a lo que nos dijeron y resulta no ser verdad o verosímil pues estaba tentado por la malsana codicia de los otros. Dicho de otro modo, era víctima de los intereses. Ante ello nos rebelamos y revelamos un relato de monstruos y virtudes. Sin final, la historia se siembra sobre voluntades de mudanzas que nos llevan a admitir otros posibles itinerarios.

Por ello, este relato es compartido para su comprensión, con sentimiento, para ser soñado y, si fuera posible, creerlo. Un Prometeo que hacemos Frankenstein por haber robado el fuego, denunciando la injusticia y por haber creado con trozos de una sociedad que no se reconoce en él, sino contra él. Aunque Zeus prohibió el fuego a la humanidad, Prometeo lo desafía. La venganza se cebó sobre él. Pese a todo, los seres humanos disfrutan del fuego, es el centro del hogar... y de tantos desastres terrenales. Pero el monstruo nos da verdadera lecciones magistrales sumergiéndonos en los mundos de fantasía y la ficción (Meirieu, 1998) ya que estos enseñan y comunica.

\section{Comprensión}

¿Todo es casual? Probablemente, casi nada, o mejor dicho, nada es por una simple razón. La concatenación de los hechos está hilvanada en un continuo que, en ocasiones, forma parte del delirio que iría desde la visión a la ilusión o de la rechazable alucinación al no rotundo de su admisión. Y de repente salta el monstruo -el del otro y no el que nosotros alimentamos-. Claro que ruge y espumea por la boca. Lanza fuego y produce pavor. La gente, la multitud atónita sin saber el por qué lo rechaza. No es reprobado el monstruo, tal vez, sea a su propio yo -máxime cuando el monstruo está construido de sus propios iguales-. Es casi idéntico al prójimo y su nariz nos recuerda a alguien. De repente, el lector habrá imaginado que se puede tratar de un Frankenstein de aquí y ahora. El más parecido al que escribiera hace 200 años Mary Shelley, una joven inglesa hija de filósofos que dejaron en su legado un valor del que ella hizo literatura. Gracias al teatro y al cine, su obra se divulgó por nuestros pareceres. Ya vimos en la gran pantalla a un monstruo enorme en los años 30, nos hizo reír con uno jovencito y vivos que hablaba y sentía antes de finales del siglo XX (Muñoz García, 2003). En todos los casos sufrimos con la incomprensión de los demás hacia él, la extrañeza o el rechazo de la multitud que intenta acabar con lo diferente antes de comprenderlo. No interesa la diversidad. Se oculta o se aniquila. Algo parecido sucedía en el modelo social y educativo. A las personas diferentes se llegó a reservar en la casa. 


\section{I: In delirium... Formas de entender la educación, la comunicación y la vida}

No salían, hasta era motivo de recelo hacerlos públicos. Posteriormente, cuando salieron, se les pusieron nombres que los determinaban -en ocasiones, cargados de connotaciones peyorativas-. La diferencia se visualiza y se hace viral. Están en la calle y entran en la escuela. Antes aquellas personas no frecuentaban el aula, luego se les lleva a aulas específicas y, por último, se habla de integración para, más tarde, dígase inclusión. Si bien quien es diferente puede llegar a sentir y pensar como el resto de los mortales pues habla y se expresa con propiedad, quizás necesita de algo a más que el resto: le sobraba sobreprotección. Seguramente nos equivocábamos. Quizás por eso ahora la diversidad se evidencia en que ellos y ellas trabajan, no sólo como reponedores mecánicos en un supermercado o llevando cartas de un lugar para otro, sino también como personal cualificado pues han cursado carreras universitarias y poseen responsabilidades. La escuela y la Universidad, les forma para vivir una vida como el resto. Los padres y madres, en unión con los familiares, han logrado eliminar al monstruo y hacerlo el más querido de los seres humanos. Para lograr la deseada normalidad o, mejor dicho, habitualidad, lo que más necesitábamos era simplemente comprensión.

El monstruo ha dejado de tener los pies grandes, la boca pequeña, la nariz doblada y las manos deformes. Ahora parece que camina como nosotros, habla de la misma manera que nosotros, la nariz le embellece el rostro y sus manos acarician como las nuestras. El monstruo se comprende y humaniza -algo que le faltó al Frankenstein del ayer-.

Él emerge en el siglo XXI (Agamben, 2012) y nos enseña del mismo modo que su yo pasado. Tan solo la capacidad de comprensión es toda una evidencia. Son aquellos Frankenstein del ayer, los que nos han dado tantas lecciones que casi nadie los cuestiona en la actualidad. Las leyes los amparan y la ciudadanía reivindica su respeto. Pese a quienes no admiten la diversidad, todos a una aprendemos de la generosidad de Prometeo y avanzamos compartiendo el fuego que se nos entregó.

\section{Sentimientos}

El monstruo nos ha enseñado a vivir pues siente. Todo el discurso o al menos gran parte del mismo se ha centrado en su pensamiento. El nuestro se ciñe sobre el sentimiento pues qué mejor que pensar y sentir. Lo uno lleva a lo otro aunque existió una gran preocupación sobre el pensar y nos despreocupamos sobre el sentir. No obstante, una cuestión se aprende junto a la otra, y viceversa.

Nuestro monstruo ahora piensa y siente. Le hemos desprovisto de lo espantoso y lo esperpéntico. Quien lo mire actualmente lo verá embellecido y el sustantivo deformidad se atenúa. Lo miramos e incluso llegamos a admirarlo. Atemperado, el monstruo se le llama por su nombre y apellidos. Sonríe, pues el ser humano aprende -también por imitación-. Anda recto pues se le ha enseñado hasta sentarse como los demás pero comprueba, ya que piensa y siente, que los otros se sientan cómo quieren y cuándo quieren. Aún ha de aprender por sí solo a sentarse de determinada manera según el contexto y las personas. Ese aprendizaje social lo ha de adquirir con los demás. Es lo más parecido a los versos de Antonio Machado de: "caminante no hay camino, se hace camino al andar".

De una metáfora sobre el monstruo hemos evolucionado a los versos del caminante. Qué ingenuidad. Todo dependía simplemente del enfoque. El al fin 


\section{II: Educación y comunicación en los mundos de fantasía y ficción}

humanizado que piensa y siente ha de ir mejorando como los demás. No se le ha de pedir ni más ni menos. Se puede equivocar y, según el caso, no reprochárselo pues en el ayer lo tratamos como un monstruo. Ahora el desvarío forma parte de su pasado. No está anclado a ello. Otea el horizonte y mira al futuro.

El ser que siente y que ahora vemos aprecia las cosas bellas de la vida; ha aprendido a rechazar lo que no le interesa; concibe la diferencia entre el bien y el mal pero, al igual que los demás, se le ha de permitir equivocarse pues las segundas y terceras oportunidades existen también para ellos - como a todo el mundo-; observa y considera tanto en público como en privado y no ha de tener miedo ni de hablar ni de expresarse. Tal como anda erguido y con el mentón recto, su mirada ha de ser serena pero segura. Se le permite opinar, creer y abrigar sueños como el resto de los humanos ya que, aunque no todos y todas piensen como él, no debemos olvidar que eso nos pasa también al resto de los mortales. Además, no todos aceptan su derecho al fuego pero tampoco todo el mundo admite a todo el mundo. Por ello, más que nunca, debe aprender a seleccionar; a ser comedido y superar los conflictos sin acudir con ligereza a la violencia; comprendiendo que los otros también son diferentes y merecedores del mismo trato y fuego. Mientras tanto sueña... sueña con soñar.

\section{Soñando}

Para quienes consideramos la utopía como una posible realidad del mañana, tal como lo sugiere Paulo Freire, la acción de soñar resulta de lo más polisémica que se podría encontrar. Se puede aplicar a la diversidad y se semantiza por sí sola; puede ser un ideal con el cual se llega a fantasear que vira en un momento determinado en delirio; o puede ser una manera de imaginar tras un proceso de reflexión o simplemente una añoranza. Es también evocar, como un recuerdo que rememora y nos invita a vivir. Hay quien lo interpreta como un anhelo -y no precisamente como una codicia sino como un deseo al que acariciar, hacerlo verdad- (Barthes, 1972). Otros lo relacionan con dormir, un momento de nuestras vidas del cual no se puede prescindir pues reposamos y descansamos. Quién sabe... soñamos despiertos. Lo único malo de la ensoñación es que uno se despierta y afronta la cruda realidad (Zubiri, 2005). No obstante, la ensoñación ya ha modificado nuestro parecer, pero... ¿y el de los demás? Es entonces cuando el sueño entra en confrontación con los que dicen que no es conveniente soñar y nuestro hombre o mujer del relato quiere seguir soñando. Ahora bien, ha de saber diferenciar entre razonar y soñar o de lo contrario los incomprensibles e intolerantes se burlarán y rechazan.

Aun así, el hombre o la mujer diferente deben seguir soñando y diseñar su castillo en el aire. ¿Quién no lo ha hecho en algún momento en su vida? Eso sí, rescatando por similitud la alegoría de Platón, nos parece oportuno recordar que la mesura y la pasión deben equilibrar su auriga -y también el nuestro-. Soñamos que, si aquellos a los que consideramos monstruos en el pasado lograsen no hacer caso a las burlas, tal vez los otros que aún les señalan podrían contagiarse de la ensoñación. Pese a todo y todos nuestro hombre o mujer, niño o niña, anciano o anciana ha de crecer en la más absoluta cotidianeidad (Certeau, 1994). No deben vivir en una burbuja aislada del mundo que pueda desinflarse o caer en crisis tras ser azotada por la adversidad. Ese particular también se ha de trabajar. No 


\section{I/: In delirium... Formas de entender la educación, la comunicación y la vida}

hay que preocuparse en demasía por los intolerantes pues también pueden ser capaces de reponerse ante la adversidad.

El sueño no se ha diluidos, se ha transformado. En nuestras mentes existe una bien intencionada voluntad de mejora. Eso es soñar, creer en un ser humano que mejora y sentir que es posible. La incomprensión nos lleva creer lo contrario y, por la misma razón, ahora vamos a creer con él.

\section{Creer}

Del contexto brasileño nos ha inspirado un mediometraje cinematográfico basado en el asesinato de la travesti Luana en 1998: "No Coração de Shirley" (2002) dirigida por Edyala Yglesias. Bien sea por el formato o porque no se distribuyó en los grandes circuitos de exhibición, lo cierto es que la cinta pasó desapercibida para muchos sudamericanos. Recordando su historia nos preguntamos: ¿Qué pensaría la protagonista de este film sobre el monstruo que relatábamos al principio? Queremos creer que su comprensión sería mayor que la de los demás pues la protagonista sufre y es rechazada del mismo modo. Al fin y al cabo, una persona ante la diversidad sexual también se erige como un monstruo (Bourdieu, 2012). Ellos y ellas comparten el estigma de las personas con diversidad intelectual a las cuales se les tacho de aquello monstruoso que no son y sufren las mismas etiquetas que una persona con una aparente diferencia motórica o sensitiva a las que se les descalifica de incapacidad (Foucault, 2010) -todos tachados de monstruos por mentes perversas de los que se dicen llamar normales-. Estos son los que establecen el nivel de normalidad, que dicen tener un medidor mágico que indica el nivel de normalidad de unos y otros. Una aberración carente de empatía. Esos normalizadores son realmente los monstruos mientras que el conjunto social que incluye la diversidad y a los diferentes somos personas.

Queremos creer que creer es opinar sin discriminar y sin desfavorecer, dando el mismo calificativo a pensar, imaginar o estimar sin necesidad de ser calculador. Del mismo modo, entendemos que significa afirmar con confianza; manifestarse en igualdad sobre algo o alguien sin temor a ser condenado y poder admitir la propia identidad sin tener por ello que adoptar la postura de un monstruo que carga una culpa impuesta que no le pertenece. Creer es sostener un parecer igualitario y no ser cuestionado por ello. Es, incluso, poder equivocarse sin tener que ser necesariamente sentenciado por los demás.

Creer es dudar pero no tener que desconfiar. Es disentir sin verse obligado a renegar o sin temor a sembrar desconfianza. Creemos que creer es creerse una persona y no un monstruo.

\section{Despedida}

En este momento, somos incapaces de despedirnos pues suena a final. Sin embargo, todavía quedan tantas cosas por decir, por comunicar. El hecho de comunicar pareceres en el mundo de la fantasía y la ficción se asocia inmediatamente al de la imaginación. Una imaginación pobre y embrutecida ya que en ella topamos con los monstruos del hoy y de los que somos herederos. En ocasiones, conscientes o no, todos y todas podemos actuar como ellos aunque existen expertos depredadores que soslayan o eclipsan a sabiendas del daño que provocan. Son aquellos que hablan en voz alta sobre los demás vilipendiando; los incomprensi- 


\section{II: Educación y comunicación en los mundos de fantasía y ficción}

bles e irracionales que nada aportan y te chupan la sangre; aquellos y aquellas capaces de dañar y atropellar diversas sensibilidades desde una sencilla pauta: la malicia.

Mientras su delirio normalizador desea exterminar las diferencias, el nuestro es quijotesco pero sano -pues suma e integra-. Nosotros y nosotras no queremos dañar a nadie. Solo anhelamos una sociedad mejor donde actuemos como personas y donde gracias a la educación y la empatía logremos dejar de ver monstruos donde no los hay.

En conclusión, In delirium ha sido nuestra manera de decir que el monstruo del ayer desaparece gracias a quienes aprenden a ver a la persona que siempre estuvo tras los prejuicios; recordando que hay otros monstruos que se piensan normales por encima de los demás y rechazan compartir el fuego de la igualdad a la par que persiguen las diferencias -y a los hombres y mujeres que como Prometeo desean acabar con ellas-. Con la luz del fuego hemos aprendido a querer ver a esas personas comunicativas. Ahora, entendemos que comprenden, aman, proclaman, descubren, transmiten, conversan... Era todo más sencillo y nuestros prejuicios nos cegaron.

Qué gran obra la de Mary Shelley... Vivan los monstruos y sus autores pues gracias a su legado podemos educarnos y educar en empatía. La fantasía es sana, nos hacen bien y ayuda a entender la realidad.

\section{Referencias}

Agamben, G. (2012). O que é o contemporâneo e outros ensaios. Chapecó: Argos.

Barthes, R. (1972). Crítica y verdad. Siglo XXI editores: Buenos Aires.

Bourdieu, P. (2012). A dominação masculina. Rio de janeiro: Bertrand Brasil.

Canclini, N. (1998). Culturas Híbridas: estratégias para entrar e sair da modernidade. São Paulo: EDUSP; 31-157.

Certeau, M. (1994). A invenção do cotidiano. Petrópolis: Vozes.

Foucault, M. (2010). Os Anormais. São Paulo: Martins Fontes

Muñoz García, J.J. (2003). Cine y misterio humano. Madrid: Rialp

Meirieu, Ph. (1998). Frankenstein educador. Barcelona: Laertes.

Zubiri, X. (2005). El hombre: lo real y lo irreal. Madrid: Alianza. 